\title{
POVOS INDÍGENAS NO BRASIL: DIREITO A TERRA E ORDENAMENTO FUNDIÁRIO
}

\author{
INDIGENOUS PEOPLES IN BRAZIL: RIGHT TO LAND AND LAND ORDINATION
}

\section{Douglas Oliveira Diniz Gonçalves}

Mestrando em Direitos Humanos pela Universidade Tiradentes.

E-mail: douglas_odg@hotmail.com

\section{Fran Espinoza}

Phd. Professor do Mestrado em Direitos Humanos, UNIT, Aracaju. Doutor em Estudos Internacionais, Universidade de Deusto, Espanha. Pós-doutorado em Políticas Públicas, Universidade Federal do Paraná, Brasil. E-mail: espinoza.fran@gmail.com

Recebido em: 03/10/2019

Aprovado em: 07/05/2020

\begin{abstract}
RESUMO: Os povos indígenas na América Latina, desde a época colonial, sofrem com inúmeras e contínuas violações a seus direitos, dentre eles e mais intensamente o direito coletivo as suas terras ancestrais. Agregados sem o reconhecimento de suas particularidades ou apartados em desconsideração das condições inequânimes às quais estão expostos, os povos indígenas arcam com a precariedade no sopesamento entre diferença e igualdade. Tendo em vista tal problemática, o objetivo da presente pesquisa é analisar um mecanismo eficaz de concretização do direito a terra dos povos indígenas, levando em conta as tensões entre o direito à igualdade e o direito à diferença. Assim, o presente estudo levanta a seguinte pergunta: a confluência de lutas pelo ordenamento fundiário pode representar um caminho possível e efetivo para a concretização do direito a terra dos povos indígenas? A partir dessa indagação, conclui-se que a confluência de lutas pela terra, sob um mesmo pleito amplo em prol do ordenamento fundiário se desponta como uma forma eficiente de exercer pressão social e política sobre os Estados a fim de promover a efetivação dos direitos à terra.
\end{abstract}

Palavras-chave: Direito à diferença; direito à igualdade; ordenamento fundiário.

ABSTRACT: Since colonial times Indigenous peoples in Latin America have suffered numerous and continuous violations against their rights, and more intensely against their right to the ancestral lands. Aggregated without the recognition of their particularities or parted in disregard of the unequal conditions to which they are exposed, indigenous peoples continuous to bear the disadvantages of the precarious articulation between difference and equality. The goal of this paper is to analyze by taking into account the tensions between the right to equality and the right to difference if an effective mechanism for the realization of indigenous peoples' land rights can be achieved. Thus, it is questioned if: does a confluence of struggles for land ordination represents a 
possible and effective pathway to the realization of the right to land of indigenous peoples? Answering this proposition drops into the conclusion that the confluence of struggles for land access, under an umbrella claim for land ordination, emerges as an efficient mecanism to insert social and political pressure on the national states for them to promote all the different types of land rights.

Keywords: Right to difference; right to equality; land ordination.

SUMÁRIO: Introdução; 1 A igualdade que descaracteriza; 2 A diferença que inferioriza; 3 Por diferenças agregadas rumo à igualdade; Considerações finais; Referências.

“(...) não é só direitos iguais que a gente precisa. Somos povos indígenas e queremos ter o direito à diferença também.

Sônia Guajajara, 2019, p.33.

\section{INTRODUÇÃO}

Os povos indígenas na América Latina, desde a época colonial, sofrem com inúmeras e contínuas violações a seus direitos, dentre eles e mais intensamente o direito às suas terras ancestrais. Sem negar a relevância dos movimentos indígenas das últimas décadas na consolidação da luta por suas demandas particulares, a presente pesquisa suscita a tensão entre os direitos à igualdade e à diferença como base para a propositura de formas efetivas de realização do direito coletivo aos territórios dos povos indígenas.

A problemática recai sobre a intrincada equalização entre os direitos à igualdade e à diferença que, embora aparente tratar de um percalço à realização dos direitos territoriais dos povos indígenas, também se desponta como um legítimo parâmetro para a efetiva concretização do direito a terra.

Para isso, foge-se tanto de um agregamento homogeneizante do pleito territorial indígena a outras demandas, responsável pelo esvaziamento das peculiaridades culturais dos povos em momentos passados, como também de uma diferenciação geradora do afastamento excludente da luta territorial indígena de outros campos de pressionamento, compartilhados com os demais grupos sociais, separação esta que os relegou às antigas condições de inequidade.

Partindo-se desses insucessos experimentados na luta pelo direito a terra, quando generalizada dentro da luta por reforma agrária e mesmo depois com a separação em um pleito específico por território no contexto da Emergência indígena, chega-se ao objetivo da presente pesquisa que é: analisar se levando em conta as tensões entre direito à igualdade e direito à diferença pode-se chegar a um mecanismo eficaz de concretização do direito a terra dos povos indígenas.

A partir do qual, levanta-se a seguinte pergunta: a confluência de lutas pelo ordenamento fundiário pode representar um caminho possível e efetivo para a concretização do direito a terra dos povos indígenas?

Como confirmação desse questionamento, chega-se à conclusão de que a confluência de lutas pela terra, sob o pleito amplo em prol do ordenamento fundiário, feito por grupos diversos como os povos indígenas, o campesinato e as comunidades quilombolas, quando respeitadas as peculiaridades de suas demandas específicas, se desponta como uma forma eficiente de exercer pressão social e política sobre os Estados a fim de promover a efetivação dos direitos à terra.

Fala-se em direitos, entendidos no plural, por se tratarem de variedades de um mesmo pleito, que devem ser conjugadas sob o fim de se alcançar a igualdade e, ao mesmo tempo, particularizadas em razão das diferenças essenciais às suas expressões. 
O método aplicado à presente pesquisa é de caráter qualitativo, em razão do uso de formulações feitas por pesquisadores das áreas da sociologia, ciência política, antropologia e direito, além da remissão a textos normativos do ordenamento brasileiro e internacional de direitos humanos, a fim de dar robusteza à argumentação central.

Parte-se da proposição, elaborada por Boaventura de Sousa Santos (1997), que equaciona os direitos à igualdade e à diferença numa mesma fórmula, tomando-a como eixo e fundamento da demonstração feita na presente pesquisa, qual seja, a de que: reconhecidas as peculiaridades do direito a terra dos povos indígenas (direito à diferença), tal direito merece o mesmo grau de realização e proteção conferido à propriedade privada e aos demais direitos subalternos à terra (direito à igualdade).

Tal formulação serve de marco e guia na divisão e gradação lógica dos capítulos que se seguem sob os seguintes tópicos: 1 - A igualdade que descaracteriza; 2 - A diferença que inferioriza; e 3 - Por diferenças agregadas rumo à igualdade.

Em "A igualdade que descaracteriza", é posta em evidência a Emergência indígena, mobilização de papel fundamental na particularização das lutas indígenas por seus territórios, bem como na promoção de suas identidades enquanto povos. O intuito é demonstrar que a anterior generalização da luta indígena, sob a mesma identidade que a luta do campesinato, descaracterizava a real demanda coletiva dos povos por suas terras. Contudo, apesar de exitosa no ressituamento da luta, destaca-se que a emergência indígena não gerou os efeitos imaginados, sendo falha na efetivação dos direitos demandados perante os Estados. Assim, diante de uma igualdade descaracterizadora, funda-se a necessidade de serem observadas as peculiaridades dos pleitos dos povos indígenas por suas terras, restando clara a importância do direito à diferença.

Em “A diferença que inferioriza", parte-se do cenário de exclusão normativa dos direitos dos povos indígenas nos âmbitos jurídicos nacionais e internacional, para então demonstrar o movimento paulatino de inclusão dos mesmos como resultado da Emergência indígena. Chega-se assim à constatação de um esgotamento das vias de luta utilizadas desde então, o que aponta a necessidade de se exercer uma pressão local, pleiteando as demandas específicas dos povos indígenas perante os Estados nacionais.

Já em "Por diferenças que se agregam rumo à igualdade", a proposta fundamental da presente pesquisa toma sua forma. Baseando-se na ideia de Joaquín Herrera Flores (2009) de articulação das múltiplas e diferentes formas de luta pela dignidade humana para a criação de novos caminhos de ação e reflexão, recorre-se à propositura de uma união de diferentes pautas por terra, de povos indígenas, comunidades quilombolas, camponeses sem-terra e ainda referente à proteção do meio ambiente, sempre em respeito às diferenças de cada demanda particular, com o objetivo de alcançar a efetividade desses direitos.

Tal propositura busca sua validação na categoria de análise elaborada por Gallegos e Stoessel (2015) que aponta a confluência de lutas como propiciadora da construção de problemas públicos, as chamadas "querelas da sociedade", que por adquirirem uma maior pressão política, se tornam campos propícios para a efetivação de um pleito compartilhado.

Desse modo, a análise da presente pesquisa concatena as tensões entre o direito à igualdade e o direito à diferença, juntamente com a confluência de pautas de grupos sociais e culturais diversos pelo direito a terra, com o fim comum de que seja alcançado um cenário de efetivação do direito a terra dos povos indígenas no Brasil.

\section{A IGUALDADE QUE DESCARACTERIZA}

Tomando como marco a chegada dos europeus às Américas, os povos indígenas sofreram inúmeros ataques, ao seus corpos, sob a forma de genocídio; às suas culturas, sob a forma de etnocídio; e também as suas terras, sob a forma da expropriação forçada. 
Tal processo de expropriação fundiária, ou seja, de retirada dos povos de suas terras, foi e continua sendo responsável pela produção de efeitos nocivos aos povos indígenas como, por exemplo, a marginalização, a pauperização e a segregação social (OLIVEIRA FILHO, 1996, p.6). Além de, por si só, provocar a degradação das culturas e tradições ancestrais dessas culturas deslocadas forçosamente de seus territórios.

Para além disso, a conquista territorial, como processo de apagamento de identidades, encontra-se intimamente relacionada ao próprio genocídio, ao extermínio de corpos indígenas, pois, com a privação total do território-localidade ao qual se remeter, resta-se apenas com o território do corpo como último guardião da identidade (SEGATO, 2006, p.131). Assim, sob o contexto de opressão colonial, os povos indígenas sofreram e continuam a sofrer um processo sistemático e sucessivo de apagamento de seus territórios, corpos e culturas.

Segundo dados do Instituto Socioambiental, a diversidade da população indígena no Brasil é representada por 252 povos distintos, falantes de mais de 150 línguas, distribuídos em Terras Indígenas cuja área representa $13,77 \%$ do território nacional (INSTITUTO SOCIOAMBIENTAL, 2017, p.8-17), o que vem a constituir uma parcela ínfima das terras, da diversidade e da multiplicidade dos povos que habitavam Pindorama ${ }^{1}$ antes da invasão europeia.

Dada a repercussão na vida desses povos, a territorialidade, expressa sob a forma do direito a terra, se desponta como sendo a dimensão fundamental de afirmação e garantia tanto dos demais direitos dos povos indígenas quanto de suas identidades coletivas (SANTOS e NUNES, 2003, p.45). É exatamente pela importância que a terra assume na preservação desses povos que a mesma se torna alvo fácil de sua precarização e de seu extermínio.

Não à toa, até os dias atuais, uma das maiores dificuldades encontradas pelos povos indígenas, no contexto de efetivação de seus direitos humanos, continua sendo exatamente a pressão econômica sofrida sobre suas terras, territórios e recursos naturais (NAÇÕES UNIDAS, 2013, p.4).

Foi como reação às desigualdades e à marginalização sofridas por esses povos desde a colonização que irromperam-se, na América Latina, movimentos de mobilização indígena em prol da efetivação de seus direitos e do atendimento de suas pretensões coletivas.

Tal insurgência, cujo ápice se deu em meados dos anos 90, ficou conhecida como a Emergência indígena e foi marcada como um processo tanto de recuperação do orgulho e da autoestima dos povos (ESPINOZA, 2011, p.4), como também de resistência e de reconstrução de identidades (BENGOA, 2009, p.8). Esses foram os aspectos diferenciais do movimento, visto que pela primeira vez os povos indígenas surgiam como porta-vozes de seus próprios pleitos na luta pela concretização de seus direitos.

Antes da Emergência indígena, esses povos encontravam-se mesclados sob a categoria do campesinato como forma de pleitear frente ao Estado suas demandas por terra (ESPINOZA, 2017, p.91). Contudo, sua luta se focava na questão da reforma agrária, uma categoria mais abrangente de pleito sobre a terra que não necessariamente incluía as percepções e as relações particulares dos povos com seus territórios ancestrais.

Tal situação provou ser uma das razões para o fracasso de suas demandas, pois essa falsa igualdade à classe camponesa demonstrou produzir uma verdadeira descaracterização das peculiaridades dos povos indígenas e de seus direitos, em especial, o direito coletivo as terras que tradicionalmente habitam.

Os povos entenderam naquele momento que suas lutas haviam sido assimiladas e subordinadas às lutas classistas campesinas, o que reduzia a abrangência de suas demandas, pois como povos indígenas percebiam que não só haviam sofrido a exploração individual a qual passavam os camponeses, como também haviam sido sistematicamente oprimidos como povos e nações. Assim, foram se desenvolvendo discursos mais elaborados sobre territorialidade e

\footnotetext{
${ }^{1}$ Nome dado à extensa região do litoral brasileiro e que, em tupi-guarani, significa "terra das palmeiras".
} Revista de Direito Brasileira | Florianólopis, SC | v. 25 | n. 10 | p. $72-85$ | Jan./Abr. 2020 
autonomia (ASSIES, 2007, p.234-235), assumindo para tanto que o papel da terra dentro do pleito dos povos indígenas se distingue fundamentalmente daquele desempenhado pela propriedade privada para o campesinato.

A diferença essencial entre a luta pela terra, genericamente considerada, e a luta pelo território é que, para os povos indígenas, o território não representa apenas a terra agrícola necessária para sua subsistência alimentar, mas também é a raiz de sua própria identidade cultural. O território representa seus antepassados, sua cultura, suas tradições, seus costumes e suas crenças religiosas, compondo assim, toda a sua memória histórica enquanto povos (SANTOS, 2012).

A partir da leitura do art. $231, \S 1^{\circ}$, da Constituição brasileira de 1988, pode-se depreender, como asseguradas, essas diferentes matizes e funções assumidas pela territorialidade indígena, dispondo o primeiro parágrafo do artigo supracitado, que:

Art. 231.

$[\ldots]$

$\S 1^{\circ}$ São terras tradicionalmente ocupadas pelos índios [1] as por eles habitadas em caráter permanente, [2] as utilizadas para suas atividades produtivas, [3] as imprescindíveis à preservação dos recursos ambientais necessários a seu bemestar [4] e as necessárias a sua reprodução física e cultural, segundo seus usos, costumes e tradições [numeração acrescida] (BRASIL, 1988).

Das categorias representadas pelos números 1 e 2, pode-se aferir dois conceitos de fácil correspondência à ideia ocidental de propriedade, sendo o primeiro equivalente ao direito à moradia e o segundo à utilização da terra para fins econômicos. Já, das duas últimas, números 3 e 4 , podem ser percebidas concepções que fogem ao conceito tradicional de terra como entendido pelo Ocidente, qual seja, assumindo o viés do direito ao meio ambiente equilibrado e também como local de acesso aos recursos naturais necessários para o bem-viver dos povos, e, mais intensamente, como condição imprescindível para a manutenção dos vínculos culturais, religiosos e ancestrais dos povos indígenas.

Tendo em vista suas peculiaridades, as territorialidades indígenas, expressas no direito coletivo a terra, tiveram seu conteúdo escasseado quando incorporadas às lutas por reforma agrária, pois o objeto de proteção e garantia da propriedade privada por si só não era capaz de abranger toda a dimensão que os territórios assumem para a vida desses povos. Foi nesse contexto que a ruptura da luta indígena na América Latina perante os movimentos campesinos por reforma agrária se despontou como o marco inicial de uma luta efetiva e particularizada pelos territórios. Antes, incorporados a uma luta que não era exatamente a sua, os povos indígenas tiveram suas reais demandas encobertas por uma igualdade que os descaracterizava.

Foi precisamente o rechaço à permanência sob a categoria de camponeses a marca fundamental do surgimento dos novos movimentos indígenas, sendo um aspecto essencial para tanto o debate sobre a distinção entre classe e etnicidade. Através do questionamento dessa diferença, os povos indígenas puderam formular suas identidades próprias tomando como contraste o campesinato (ESPINOZA, 2017, p.94). Sendo que o maior desses contrastes se deu em razão do modo de vida sedentário dos agricultores, o que fez insurgir a necessidade de se pleitear demandas territoriais específicas e distintas (ASSIES, 2007, p.234).

Nesse cenário, a demanda pelo território tornou-se palco desses processos de reconhecimento étnico e construção das identidades coletivas indígenas, servindo também de local para a representação das identidades, já que tantos as paisagens humanas como as geográficas conformam umas às outras, são os símbolos culturais em que os povos se reconhecem e através dos quais também passam a ser reconhecidos (SEGATO, 2006, p.131). Assim, a compreensão do 
conceito de território ultrapassou o reducionismo fisiográfico ocidental, alcançando sua ampla significação cultural, social e política (LLANOS-HERNÁNDEZ, 2010, p.219).

Para além da influência na construção das identidades étnicas dos povos indígenas, a luta por seus territórios repercute também no assentamento da ideia de território fechado nessas culturas, o que ocorre em decorrência das restrições impostas pelos processos estatais de regularização fundiária. Assim, sob a égide do Estado, os territórios, construídos e vivenciados de formas culturalmente variadas pelos povos indígenas, sem terem necessariamente uma dimensão material, são transformados em terras indígenas, sob uma nova concepção de posse e propriedade (GALLOIS, 2004, p.39), estando aptos então a serem objeto da proteção jurídica instituída pelo Estado e concretizada através do processo de demarcação de terras.

Apesar de o direito a terra dos povos indígenas ser reconhecido no Brasil, inclusive em seu caráter originário, o que significa que sua existência e concretude como direito prescinde de qualquer regulamentação por parte do Estado, observa-se sua contínua e persistente falta de efetividade. Tal cenário é compartilhado por toda a América Latina, onde, ainda que reconhecidos, os territórios indígenas são constantemente desrespeitados ou efetivamente invadidos.

Percebe-se, portanto, que a emergência indígena fracassou na obtenção concreta e imediata de suas demandas específicas, a exemplo do direito ao território. A despeito disso, foi exitosa em muitos aspectos, como no alcance de um patamar de destaque para a questão étnica dos povos indígenas. Assim, se diz que, apesar de não produzidas conquistas materiais a curto prazo, a emergência indígena teve como triunfo a criação de uma historicidade, responsável pela implantação da temática dos direitos indígenas no contexto político da América Latina (BENGOA, 2009, p.11-12).

Levando em conta o êxito da Emergência na dimensão identitária dos povos indígenas, percebe-se que a antiga generalização dessas coletividades sob a mesma pauta da reforma agrária, encabeçada pelo campesinato, ocasionou o apagamento de suas demandas próprias, através da esterilização das diversas dimensões assumidas por suas territorialidades. Assim, essa mobilização serviu de contributo eficaz para que os povos indígenas abandonassem uma igualdade que os descaracterizava em prol da luta por sua diferença.

\section{A DIFERENÇA QUE INFERIORIZA}

Dentro de uma conjuntura colonial de imposição, marcada pelo sistemático apagamento dos povos, em suas identidades, culturas e corpos, o espectro da diferença assume uma posição de destaque como um conceito fundamental para a separação entre aqueles que chegavam da Europa e os nativos encontrados nas Américas.

Essa necessária distinção se fez, dentre outras formas, através de diferenças calcadas na ideia de raça, uma nova codificação que então se formava como critério distintivo e explicativo de uma condição supostamente natural entre inferiores e superiores (QUIJANO, 2005, p.117). Foi a partir desse plano de fundo que se legitimou a conquista e a subalternização dos povos indígenas e de suas culturas.

Sob a influência do sistema jurídico internacional do século XVI, os povos indígenas foram conquistados, usurpados de sua soberania e expropriados de suas terras e territórios tradicionais. Sendo portanto a lei internacional utilizada à serventia do colonialismo e do imperialismo cultural, como instrumento de legitimação do sistema que se impunha e, consequentemente, como testemunha da aniquilação física e alienação cultural dos povos nativos (GÓMEZ ISA, 2018, p.168).

É nesse contexto que se fundamenta e se explica a exclusão dos povos indígenas na elaboração e enquanto sujeitos propriamente de direitos humanos, sendo esquecidos pelo texto da Declaração Universal dos Direitos Humanos de 1948. 
Como contraponto, há quem defenda a inclusão dos povos indígenas nesse mesmo cenário tradicional de direitos humanos, sob o argumento de que uma das características fundamentais dos direitos humanos, a universalidade, impunha consequentemente a abrangência dos direitos a todos os indivíduos e povos indistintamente (STAVENHAGEN, 2008, p.258). Ocorre que uma universalidade que se dá a partir da hegemonização de uma única cultura, a ocidental, representa o mesmo que uma igualdade descaracterizante, onde se excluem quaisquer diferenças essenciais para a expressão de outras culturas.

Apesar desse histórico de precarização das identidades e das condições peculiares dos povos indígenas perante o cenário de direito internacional, foi nesse mesmo âmbito, o internacional, que os povos indígenas lograram, séculos mais tarde, pleitear por suas demandas específicas e por seus direitos coletivos, na mobilização conhecida como a Emergência indígena.

A estratégia dos povos, bem como um dos pontos mais favoráveis para a mudança de paradigma na seara do direito internacional, foi exatamente a projeção alcançada por notícias que revelavam a situação de pobreza e exclusão vivenciada pelas populações indígenas na América Latina. Assim, proporcionou-se um despertar para a questão indígena nos círculos acadêmicos e de defensores de direitos humanos (ESPINOZA, 2017, p.96).

Nas últimas três décadas, graças a esse movimento impulsionado nas escalas nacional e regional, houve um novo momento de verdadeira inserção dos povos indígenas como sujeitos de direito internacional (NAÇÕES UNIDAS, 2013, p.1). Sendo assim, tal âmbito do direito serviu como um instrumento privilegiado para o reconhecimento de suas demandas particulares e também para pleitear a reparação das injustiças historicamente perpetradas contra eles (GÓMEZ ISA, 2018, p.168).

Foi a partir de então que os direitos dos povos indígenas passaram a ser efetivamente contemplados, sob um olhar atento à suas peculiaridades, nas normas e entendimentos internacionais sobre direitos humanos.

Nesse novo cenário, em relação aos direitos territoriais desses povos, destaca-se a inovadora disposição dos artigos 25 e 26, da Declaração das Nações Unidas sobre os Direitos dos Povos Indígenas, que, além de garantirem o direito a terra, ao território e aos recursos nele presentes, predispõem os direitos de manutenção e o fortalecimento da relação espiritual entre os povos e suas terras, águas, e demais elementos da natureza (NAÇÕES UNIDAS, 2007), atendendo assim a demandas indígenas particulares nunca antes garantidas internacionalmente, através da normatização de direitos baseados na diferença.

De ainda maior relevância para a questão territorial indígena foi o entendimento jurisprudencial, cunhado pela Corte Interamericana de Direitos Humanos no julgamento do caso da comunidade Mayagna (Sumo) Awas Tingni vs. Nicarágua, por reconhecer que:

(...) Entre os indígenas existe uma tradição comunitária sobre uma forma comunal da propriedade coletiva da terra, no sentido de que o pertencimento desta não se centra em um indivíduo, mas no grupo e sua comunidade. Os indígenas pelo fato de sua própria existência têm direito a viver livremente em seus próprios territórios; a relação próxima que os indígenas mantêm com a terra deve de ser reconhecida e compreendida como a base fundamental de suas culturas, sua vida espiritual, sua integridade e sua sobrevivência econômica. Para as comunidades indígenas a relação com a terra não é meramente uma questão de posse e produção, mas sim um elemento material e espiritual do qual devem gozar plenamente, inclusive para preservar seu legado cultural e transmiti-lo às futuras gerações. (CORTE INTERAMERICANA DE DIREITOS HUMANOS, 2001, p.78). 
O documento internacional mais contundente na representação dessa mudança de paradigma foi e continua sendo a Declaração das Nações Unidas sobre os Direitos dos Povos Indígenas de 2007.

Através dela consolidou-se a necessidade do compromisso de os Estados reconhecerem, respeitarem e promoverem os direitos específicos dos povos indígenas, com especial ênfase aos de matriz coletiva, como resultados de suas culturas, crenças, histórias, concepções de vida e estruturas políticas, sociais e econômicas (KAINGÁNG, 2008, p.17).

Sendo também um aparato intencionado à reparar as injustiças cometidas no passado contra os povos, injustiças essas que explicam em grande parte as exclusões sofridas no presente pelos mesmos (GÓMEZ ISA, 2019, p.126). Nesse ponto, os povos indígenas souberam utilizar do direito internacional contemporâneo como um forte aliado em sua luta por reconhecimento e pela eliminação de padrões de subjugação, expropriação e assimilação cultural enraizados historicamente (GÓMEZ ISA, 2018, p.187).

Todavia, assim como se reconhece o papel do âmbito jurídico internacional como cenário auspicioso para o reconhecimento da situação em que vivem os povos indígenas, é imprescindível ter em mente que as normas e os instrumentos internacionais são criados pelos Estados e para os Estados (KAINGÁNG, 2008, p.16). Assim, devemos ser conscientes de que tais avanços observados no plano jurídico internacional têm suas limitações e enfrentam grandes dificuldades no tocante à sua implementação (GÓMEZ ISA, 2019, p.120).

Desse modo, ao menos que sejam resolvidos os detalhes práticos responsáveis pela falta de efetividade dos direitos, melhorando os mecanismos de proteção e promoção de direitos humanos, os direitos dos povos indígenas seguirão sendo palavra vazia (STAVENHAGEN, 2008, p.260) presente nas declarações internacionais, e ausente da realidade vivida pelos povos.

Pode-se depreender com clareza a relevância assumida pelo direito internacional como forma de os povos demandarem seus pleitos e direitos em busca de uma potencial reparação às mazelas históricas sofridas que, além de continuarem sendo perpetradas contra as comunidades indígenas latino-americanas, geram efeitos até os dias atuais, o que em grande parte explica a situação de exclusão e pobreza em que vivem.

Assim, a partir da Emergência indígena e através do direito internacional, com o fortalecimento das identidades étnicas e com o reconhecimento das demandas específicas dos povos, a diferença pôde superar o apagamento sistêmico e o silêncio normativo a qual era submetida e tornar-se enfim reconhecida como um direito.

Contudo, observa-se já há algum tempo um escasseamento do direito internacional de direitos humanos como promotor de uma verdadeira mudança na realidade dos povos indígenas. Sendo verdade também que a Emergência indígena, movimento de função essencial para a positivação das demandas das comunidades na seara jurídica, teve seu momento estelar na década de 90, mas já demonstra uma forte tendência de esgotamento (BENGOA, 2009, p.11).

Sendo assim, é rápida a constatação de que os avanços logrados no reconhecimento do direito à diferença dos povos indígenas, sob a forma de inclusão de suas particularidades culturais em documentos internacionais de direitos humanos e pela mudança de entendimento na abrangência real de seus direitos, são contundentes e louváveis. Entretanto, há ainda muito o que ser conquistado para que se possa garantir efetividade a esses direitos.

Nesse aspecto, a situação de desigualdade, vivida pelas populações nativas da América Latina, se desponta como questão de fundamental resolução, sendo com toda certeza o tema político mais relevante da atualidade. É, portanto, imprescindível que se questionem e se proponham novas formas em que as instituições possam atuar na luta contra o abismo social existente neste que é o continente menos igualitário do mundo (MARTÍ-I-PUIG, 2007, p.138).

Também se faz necessário repensar novos caminhos de promoção e efetivação de direitos humanos, que não estejam necessariamente vinculados, como demonstrado anteriormente, à 
pressão exercida por organismos e normativas internacionais, já que esta via jurídica tem suas limitações e tende muito facilmente a se esgotar a partir da promulgação das declarações.

Assim, reconhecendo a importância das conquistas galgadas por vias internacionais, parte-se para uma segunda fase da Emergência indígena, marcada pelo exercício de poderes locais, exercidos pelos próprios povos indígenas (BENGOA, 2009, p.12). Sendo o eixo principal dessa nova etapa a preocupação com a efetividade dos direitos particulares, reconhecidos como resultado da primeira fase da mobilização, bem como com a promoção do direito à igualdade, pleiteado não somente em face da comunidade internacional, mas principalmente perante os Estados nacionais.

São exatamente essas "tensões entre a diferença e a igualdade, entre a exigência de reconhecimento da diferença e de redistribuição que permita a realização da igualdade" (SANTOS, 2003, p.25), que guiam o momento atual de luta pelos direitos dos povos indígenas. E que também direcionam o compasso da presente pesquisa na busca de formas de concretização da igualdade, sem descuidar das diferenças culturais que identificam os diversos grupos sociais.

Passado o rechaço à uma igualdade descaracterizante, como quando as demandas indígenas por território encontravam-se submersas sob os pleitos do campesinato por terra, e também superada a inferiorização da diferença, pelo menos em relação ao cenário jurídico internacional de direitos humanos, parte-se para um outro campo de luta, o da realização social do direito coletivo dos povos indígenas ao território.

\section{POR DIFERENÇAS AGREGADAS RUMO À IGUALDADE}

Como alternativa às já escassas vias jurídicas internacionais, encontradas no passado pela mobilização indígena para a promoção de seus direitos, despontam-se as vias domésticas, pautadas sob pressões por demandas locais por igualdade e que se revelam como possíveis instrumentos de concretização dos pleitos coletivos dos povos indígenas.

Para tanto, deve-se assumir uma nova postura em relação ao enfrentamento das desigualdades. Partindo-se de uma nova forma de compreender o mundo e também de irromper tendências dominantes e excludentes da diversidade, com o intuito de se desbravar caminhos de reflexão e ação, chega-se a uma condição imprescindível: o entrelaçamento e a articulação das múltiplas e diferentes lutas em prol da dignidade humana (HERRERA FLORES, 2009, p.207).

Tal evidência impõe uma reflexão sobre o desmembramento da luta indígena por seus territórios a partir de uma pauta mais generalizada por terra, encabeçada pelo campesinato. Reiterase aqui a enorme relevância histórica dessa separação, por ter sido responsável por um processo de reconstrução das identidades dos povos indígenas e também por ter afastado uma generalização descaracterizante das demandas indígenas.

Entretanto, percebe-se que, tendo já assentadas as diferenças culturais e tendo sido consolidados os reais pleitos dos povos indígenas por suas terras, um movimento "aparentemente retrógrado" de conjunção da demanda indígena com outros pleitos por terra pode se revelar como propiciador de uma maior efetivação desse direito.

Observa-se que, quando dois ou mais pleitos de grupos sociais diversos confluem sob uma mesma problemática comum contida nessas lutas, cria-se um campo de conflitividade política, movido por uma "querela da sociedade" capaz de pressionar o processo político a efetivar tais demandas (GALLEGOS; STOESSEL, 2015, p.11-12).

Assumindo uma união marcada pelas generalidades compartilhadas entre os segmentos sociais e não por imposições ou exclusões, é que se pode verdadeiramente alcançar um universalismo de contrastes, mesclas e intercruzamentos, que pretende as inter-relações e os compartilhamentos, em detrimento de hegemonias e superposições, conformando assim uma visão complexa da realidade (HERRERA FLORES, 2009, p.164-165).

É através dessa manipulação das tensões entre diferença e igualdade, que busca-se pleitear (1) pela igualdade na efetivação das demandas, dada a necessidade de se estabelecer um equilíbrio

Revista de Direito Brasileira | Florianólopis, SC | v. 25 | n. 10 | p. 72-85 | Jan./Abr. 2020 
justo em relação à efetividade concedida à propriedade privada, (2) em conjunto com as diferenças, levando-se portanto em consideração as peculiaridades das demandas por terra de cada grupo social.

Nesse sentido, para que as diferentes expressões do direito a terra sejam abarcadas dentro do mesmo pleito é imprescindível que se reconheça a diversidade de representações, percepções e cosmovisões assumidas por esse direito. Assim, devem ser reivindicadas suas mais diferentes expressões, enquanto territórios materiais: agrários, agrobiodiversos e de usufruto; e também como territórios imateriais: espirituais, sagrados e simbólicos. Ainda, devem ser entendidos como sendo territórios imersos em conflitos, tensões e disputas violentas e dolorosas (RAMOS, 2019, p.38), assumindo o direito a terra, uma feição de resistência e de luta pela sobrevivência física e cultural das comunidades.

Sendo assim, a demarcação e o estabelecimento de terras, sejam elas indígenas ou quilombolas, ou terras agrárias para uso de populações campesinas, representa a garantia de um espaço político de exercício da diferença e de projeção de um futuro de continuidade étnica dentro de uma sociedade plural (NEVES, 2012, p.165), onde a igualdade não se reduza à inferiorização e ao empobrecimento das diferenças, e sim que seja palco para a emancipação e para o exercício efetivo e igualitário das diferenças, que juntas conformam a diversidade cultural de uma sociedade nacional.

Nesse contexto, as pautas ambientais também se agregam ao pleito comum pela terra, visto que a proteção da natureza e a efetivação dos direitos territoriais dos povos indígenas encontram-se entrelaçadas de forma visceral. Assim, a concretização de uma implica necessariamente na realização social da outra (GONÇALVES; ESPINOZA; DORNELLES, 2020, p.315), trazendo mais um impulso à pauta ampla e compartilhada.

É, através dessa integração de saberes produzidos entre diferentes grupos sociais e culturais, que se propicia o alcance de uma compreensão de direito a terra intercultural e multiterritorial, que concentre uma totalidade complexa e complementar de diferenças e contradições para a formação de uma unidade sócio-territorial conjunta e amalgamada (RAMOS, 2019, p.31-32).

Tendo em vista todo o exposto, percebe-se que a falta de efetividade dos direitos dos povos indígenas e das comunidades quilombolas, de acesso a terra dos camponeses sem-terra, e de proteção ambiental, correspondem a uma problemática comum, qual seja, a inefetividade e a precarização do direito a terra, direito este que deve ser entendido de forma mais ampla e, ao mesmo tempo, mais inclusiva das peculiaridades dos povos e das comunidades que o detém.

Desse modo, as lutas pelo direito ao território dos povos indígenas, e das comunidades quilombolas, bem como as mobilizações pela reforma agrária e pelo meio ambiente protegido, confluem sob uma mesma "querela da sociedade", que pode ser resumida a um pleito conjunto por ordenamento fundiário.

Partindo-se dessa que é a proposta fundamental da presente pesquisa, é inescapável que se faça um aprofundamento na conceituação de ordenamento fundiário, categoria esta que aqui se pretende estabelecer como pleito comum das supracitadas demandas por direito a terra.

Ordenamento fundiário, ou ordenação territorial, é um processo, de caráter técnicopolítico-administrativo, cujo fim maior se dá para o planejamento e a organização do uso e da ocupação do território, em concordância com as potencialidades e limitações da terra, e com as expectativas e aspirações da população (CABEZA, 2002), sendo marcadamente um instrumento e não um fim em si próprio, um meio estratégico a serviço do bom uso dos recursos, do desenvolvimento e do bem-estar e da qualidade de vida dos cidadãos (ZOIDO, 1998, p.21).

É nesse sentido que se enxerga o ordenamento fundiário como sendo um instrumento de implementação dos direitos a terra, que os grupos sociais marginalizados detêm, em plena expressão conjunta de suas peculiaridades. Assumindo, portanto, o caráter de uma política pública 
de reparação das desigualdades que ocasionaram e ocasionam a precarização e a inefetividade de suas demandas.

Cumpre-se assim a função pública do ordenamento fundiário, que diz respeito ao controle do crescimento espontâneo das atividades humanas e dos problemas e desequilíbrios gerados por esse crescimento. Com isso, busca-se a realização de uma "justiça sócio-espacial" que transcenda um mero crescimento econômico (GÓMEZ OREA, 1994, p.2) na geração de um desenvolvimento que seja efetivo para os mais diversos grupos sociais.

Longe de se tratar de um instrumento perfeito e infalível, o ordenamento fundiário deve ser entendido também a partir das falhas mais corriqueiras em sua implementação que, segundo Cabeza (2002), costumam ser principalmente a falta de participação social, a falta de claridade nos eixos de ação do ordenamento do território e a falta de respaldo legal através de normas reguladoras.

Diante das questões relatadas, pontua-se que o ordenamento fundiário, enquanto proposto na presente pesquisa, entendido a partir de um pleito comum surgido da confluência de lutas distintas por direitos a terra, tem sua própria origem na participação social. Sendo, então, pensado como resultado de uma pressão conjunta exercida por grupos sociais marginalizados.

Quanto ao problema de uma possível falta de claridade nos eixos de ação, tem-se como solução o exercício do direito à diferença, através do atendimento das peculiaridades assumidas pela terra para cada um dos grupos e pleitos em questão. Assim, cada particularidade cultural e social dos territórios deve ser entendida como um eixo a ser cumprido no processo de ordenação da terra.

Já em relação à ausência de lei que regulamente a matéria, tal questão pode ser tanto uma oportunidade de emancipação, visto que a pressão social exercida em conjunto pode influir na criação de uma legislação que contemple o pleito por terra em todas as suas peculiaridades, como também pode se tornar uma ferramenta para a obstação das demandas por terra, se produzido um texto normativo que atenda apenas interesses hegemônicos, ou seja, daqueles que já detêm o uso e a propriedade da maior parte das terras.

Dada essa dubiedade do resultado alcançado por uma legislação, deve-se ter em mente que a pressão pela realização das demandas concretas, ou seja, a luta pela concretização do pleito, é mais relevante e eficiente para o alcance do fim almejado que a espera de uma resolução advinda única e exclusivamente através de um corpo normativo que regulamente a situação das terras no país.

É nesse sentido que se propõe a união de pautas distintas em prol de uma solução em comum ao problema da inefetividade do direito a terra no Brasil, devendo ser fundamentalmente guiada pela máxima de que "(...) as pessoas e os grupos sociais têm o direito a ser iguais quando a diferença os inferioriza, e o direito a ser diferentes quando a igualdade os descaracteriza" (SANTOS, 1997, p.122).

Nesse contexto, a confluência de um pleito comum por ordenamento fundiário se desponta como sendo um instrumento possível, emancipador da situação de desigualdade enfrentada pelos povos indígenas do Brasil em razão da precarização e não realização de seu direito originário as terras.

\section{CONSIDERAÇÕES FINAIS}

A partir do questionamento levantado, de que a confluência de lutas pelo ordenamento fundiário pode representar um caminho possível e efetivo para a concretização do direito a terra dos povos indígenas, construiu-se toda a validação demonstrada acima e através da qual se alcançou uma resposta afirmativa.

Partindo-se da tensão entre o direito à diferença e o direito à igualdade, chega-se a uma formulação de grande potencial emancipador, na qual a igualdade deve ser entendida como direito 
capaz de instrumentalizar a reparação de uma diferença construída a partir da marginalização, sem que seja um direito nocivo às diferenças intrínsecas e peculiares dos povos. Da mesma forma, a diferença deve ser compreendida como valor capaz de fortalecer identidades e de solidificar demandas particulares de grupos distintos, sem que seja usada como fator de depreciação dos mesmos.

Tendo em vista tal equacionamento, e ainda levando em consideração o histórico da luta indígena por suas terras tradicionais na América Latina, constatou-se que a união de pautas distintas que dizem respeito ao acesso, à efetividade e à proteção da terra se configura como um caminho possível a ser seguido em prol de uma maior efetivação do direito a terra dos povos indígenas.

Através da conjunção da luta dos povos indígenas pelas terras por eles tradicionalmente ocupadas com as pautas pelo acesso a terra e pela reforma agrária dos camponeses sem-terra, a titulação das terras das comunidades quilombolas, e a proteção do meio ambiente, há o surgimento de um pleito "guarda-chuva", maior e mais generalizado, respeitoso às especificidades próprias de cada grupo, e organizado sob a identidade de uma demanda por ordenamento fundiário, que se desponta como um caminho eficaz e capaz de concretizar os direitos específicos a terra, inclusive o direito coletivo ao território dos povos indígenas.

\section{REFERÊNCIAS}

ASSIES, Willem. Los pueblos indígenas, la tierra, el territorio y la autonomía en tiempos de globalización. In: MARTÍ I PUIG, Salvador. (ed.) Pueblos indígenas y política en América Latina. El reconocimiento de sus derechos y el impacto de sus demandas a inicios del siglo xxi. Barcelona: Fundació CIDOB, 2007.

BENGOA, José. ¿Una segunda etapa de la emergencia indígena en América Latina? Cuadernos de antropología social. Buenos Aires, n.29, pp. 07-22. 2009.

CABEZA, Ángel Massiris. Ordenación del territorio en América Latina. Scripta Nova, Barcelona: Universidad de Barcelona, v.6, 2002.

CORTE INTERAMERICANA DE DIREITOS HUMANOS. Caso da Comunidade Mayagna (Sumo) Awas Tingni Vs. Nicarágua. Sentença de 31 de agosto de 2001.

ESPINOZA, Fran. La lucha por el derecho a la participación política de los indígenas en América Latina. REVISTA JURÍDICA DIREITO \& PAZ. Lorena-SP, ano IX, n. 36, p. 83-102. 2017.

ESPINOZA, Fran. Pueblos indígenas: ¿Y después de la emergência? Working Papers, CriDIS, Université catholique de Lou, p. 1-24, 07 jan. 2011.

GALLEGOS, Franklin Ramírez. STOESSEL, Soledad. Campos de conflictividad política y movimientos sociales en el Ecuador de la Revolución Ciudadana. Plural, Revista do Programa de Pós Graduação em Sociologia da USP. São Paulo, v.22.1, 2015, p. 4-29.

GALLOIS, Dominique Tilkin. Terras ocupadas? Territórios? Territorialidades? In:

RICARDO, Fany (org.). Terras Indígenas e Unidades de Conservação da natureza: o desafio das sobreposições. São Paulo: Instituto Socioambiental, 2004. 
GÓMEZ ISA, Felipe. International Law, Ethno-Cultural Diversity and Indigenous Peoples' Rights: A Postcolonial Aproach. In: PENTASSUGLIA, Gaetano. (ed.) Ethno-cultural diversity and human rights. Boston: Brill, 2018. International studies in human rights, v. 122. pp. 168-187.

GÓMEZ ISA, Felipe. La declaración de las naciones unidas sobre los derechos de los pueblos indígenas: un hito en el proceso de reconocimiento de los derechos indígenas. Revista Española de Derecho Internacional, v. 71/1, 2019, Madrid. pp. 119-138.

GÓMEZ OREA, Domingo. Ordenación del Territorio: una aproximación desde el medio físico, Madrid: Instituto Tecnológico Minero de España, Editorial Agrícola Española, S.A. 1994.

GONÇALVES, Douglas Oliveira Diniz. ESPINOZA, Fran. DORNELLES, Carla Jeane Helfemsteller Coelho. Povos indígenas e meio ambiente: o conflito aparente de direitos no caso povos Kaliña e Lokono versus Suriname. Revista Direitos Culturais, Santo Ângelo, v. 15, n. 36, mai/ago, 2020. p. 307-327.

GUAJAJARA, Sônia. Tembetá. Revista de Cultura. Rio de Janeiro: Beco do azougue, 2019.

HERRERA FLORES, Joaquín. A (re)invenção dos direitos humanos. Florianópolis: Fundação Boiteux, 2009.

INSTITUTO SOCIOAMBIENTAL. Povos indígenas no Brasil 2011/2016. São Paulo: Instituto Socioambiental, 2017.

KAINGÁNG, Azelene. Histórico da Declaração. In: FRANCO, Fernanda. (org.) Um olhar indígena sobre a Declaração das Nações Unidas. Gráfica JB, 2008. pp.15-18.

LLANOS-HERNÁNDEZ, Luis. El concepto del territorio y la investigación en las Ciencias

Sociales. Chapingo: Agricultura, Sociedad y Desarrollo, v.7, n.3, 2010. pp. 207-220.

MARTÍ I PUIG, Salvador. Emergencia de lo indígena en la arena política: ¿un efecto no deseado de la gobernanza? In: MARTÍ I PUIG, S. (Ed.) Pueblos indígenas y política en America Latina: el reconocimiento de sus derechos y el impacto de sus demandas a inicios del siglo XXI. Barcelona: Fundación CIDOB, 2007. pp. 127-147.

NAÇÕES UNIDAS. Los pueblos indígenas y el sistema de Derechos Humanos de las Naciones Unidas. Folleto informativo No 9/Rev.2. Oficina del alto comisionado. Nova York e Genebra, 2013.

NEVES, Lino João de Oliveira. Volta ao começo: Demarcação emancipatória de Terras Indígenas no Brasil. Tese de doutorado. Faculdade de Economia da Universidade de Coimbra. 2012.

OLIVEIRA FILHO, João Pacheco. Viagens de ida, de volta e outras viagens: os movimentos migratórios e as sociedades indígenas. Revista Travessia. São Paulo: CEM, v.9, n.24, p. 5-9, jan./abr. 1996.

QUIJANO, Anibal. Colonialidade do poder, Eurocentrismo e América Latina. In: LANDER, Edgardo. A colonialidade do saber eurocentrismo e ciências sociais. Perspectivas latinoamericanas. Buenos Aires: CLACSO, 2005. pp. 117-142. 
RAMOS, David Jiménez. Geo-grafías comunitarias. Mapeo Comunitario y Cartografías Sociales: procesos creativos, pedagógicos, de intervención y acompañamiento comunitario para la gestión social de los territorios. Puebla: Camidabit-Los Paseantes, 2019.

SANTOS, Boaventura de Sousa. Democratizar el território, democratizar el espacio. [Entrevista concedida a] Susana Caló. Centro de Estudios Sociales, Coimbra, 2012. Disponível em: <http://contested-cities.net/CCmadrid/democratizar-el-territorio-democratizar-el-espacioboaventura-de-sousa-santos/> Acesso em: 08 de julho de 2019.

SANTOS, Boaventura de Souza. NUNES, João Arriscado. Introdução: para ampliar o cânone do reconhecimento, da diferença e da igualdade. In: SANTOS, Boaventura de Souza (org.) Reconhecer para libertar. Rio de Janeiro: Civilização Brasileira, 2003. pp.25-68.

SANTOS, Boaventura de Souza. Uma concepção multicultural de direitos humanos. LUA NOVA, São Paulo, n. 39, pp.105-124, 1997.

SEGATO, Rita Laura. En busca de un léxico para teorizar la experiencia territorial contemporánea. Politika. Revista de Ciencias Sociales n. 2, 2006. pp. 129-148.

STAVENHAGEN, Rodolfo. Los derechos de los pueblos indígenas: desafíos y problemas. Revista IIDH, v.48, pp.257-268. 2008.

ZOIDO, Florencio. Geografía y ordenación del territorio. Íber, Didáctica de las ciencias sociales. Geografía e Historia, Barcelona: $n^{\circ} 16$, abril 1998. Nuevas fronteras de los contenidos geográficos, pp.19-31. 